Article

\title{
The Effect of the OCB Gap on Task Performance with the Moderating Role of Task Interdependence
}

\author{
Yuha Yang ${ }^{1}$ (D) and Heesun Chae ${ }^{2, *(D)}$ \\ 1 Institute of Industrial Relations, Seoul National University, Seoul 08826, Korea; niceyang@snu.ac.kr \\ 2 College of Business Administration, Pukyong National University, Busan 48513, Korea \\ * Correspondence: hschae@pknu.ac.kr
}

check for updates

Citation: Yang, Y.; Chae, H. The Effect of the OCB Gap on Task Performance with the Moderating Role of Task Interdependence. Sustainability 2022, 14, 61. https:// doi.org/10.3390/su14010061

Academic Editors: Seung-Wan Kang, Seung Yeon Son and Eunmi Jang

Received: 16 November 2021

Accepted: 19 December 2021

Published: 22 December 2021

Publisher's Note: MDPI stays neutral with regard to jurisdictional claims in published maps and institutional affiliations.

Copyright: (c) 2021 by the authors Licensee MDPI, Basel, Switzerland. This article is an open access article distributed under the terms and conditions of the Creative Commons Attribution (CC BY) license (https:// creativecommons.org/licenses/by/ $4.0 /)$.

\begin{abstract}
Using the social exchange theory and the social cognitive perspective in group dynamics, this study seeks to examine how different individuals in the degree of engagement in organizational citizenship behavior (OCB) among members of a team (i.e., the OCB gap) can affect their work performance across varying levels of task interdependence. The research hypotheses were tested empirically using field data regarding 146 employee-supervisor dyads collected from 41 teams in South Korea. The results of the hierarchical linear modeling (HLM) analysis indicate that having a lover level of OCB engagement than the group average induces feelings of indebtedness in employees, and this sense of obligation is stronger in a high level of task dependence context. We further discuss the theoretical and practical implications of this research and suggest areas for future research.
\end{abstract}

Keywords: organizational citizenship behavior (OCB) gab; task performance; task interdependence; social exchange theory; social cognitive perspective

\section{Introduction}

Since its introduction in 1983 [1], the concept of organizational citizenship behavior (OCB) has attracted the interest of several scholars and continues to be one of the most popular topics in organizational behavior research [2,3]. With the increased dependence on work groups in organizations, interactions among team members have gained greater importance in terms of organizational performance. Thus, researchers have become increasingly focused on investigating OCB within the group context [4,5]. For example, a large discrepancy between the maximum and minimum helping behavior within teams has a negative effect on overall group performance [6]. The OCB composition among group members, such as the minimum and average levels of helping behavior exhibited by members of a team, also affected member effectiveness via the group helping norm [7-9]. According to Choi and Sy [4], the interpersonal perceptions of group members can affect employee behavior. Consequently, research has consistently argued that the differing levels of OCB among teams in an organization can have a major impact on organizational success.

Bandura [10] argued that what individuals observe and perceive within the context of their social interactions affect their thoughts and actions. In organizational teams, wherein employees need to interact with each other, it is their subjective perceptions toward the external environment that formulates their behavioral reactions toward this external environment [10]. Bommer and colleagues [7] found that employees that engaged in high levels of OCB performed significantly better in the race group OCB context than in the group OCB context, showing the important role of relative OCB levels in relation to individual performance. Therefore, from a social cognitive perspective, the employees' observation and perception of the relative OCB of their team members is likely to influence their behavioral reactions to such a situation. Several studies emphasized the importance of the relative OCB level among team members; however, these studies neglected individuals' internal perception of the OCB gap. In other words, previous studies that investigated OCB in social interactions focused on the effect of the 'external existence' of the lower or 
higher level of OCB levels within groups [6-8], failing to consider individuals' 'internal reactions' from a social cognitive perspective. To enlighten our understanding of OCB in group dynamics, this study proposes the concept of the OCB gap, which represents the perception of one's OCB in comparison to that of team members. By examining the effect of the OCB gap on task performance, we attempt to investigate the inter-member dynamics of OCB among group members from a social cognitive perspective [11].

Since task performance has been the traditional and primary focus of previous OCB studies [12], this study investigates the relationship between the OCB gap perception and task performance. We adopted social exchange theory [13] to examine the relationships hypothesized in this study given that the influence of OCB on performance is examined based on social exchange theory [13] and the norm of reciprocity [14]. This theory and norm may well explain individuals' reactions to the perceived OCB gap. When individuals perceive a relative difference in OCB among group members and find out that their coworkers share more resources and exhibit favorable behaviors with goodwill, their intention to reciprocate these actions to their coworkers will become greater.

There has been a continuous call for more attention to be paid to the issue of contextual moderation in the OCB literature [15-17]. As Organ [18] argued that task interdependence may increase the effectiveness of OCB in terms of job task completion. Hence, in this study, we investigate the interactive role of task interdependence on the relationship between the OCB gap and task performance.

In summary, by integrating the social exchange theory [13] and social cognitive perspective in group dynamics [11], we propose the OCB gap as an individual-within-group construct that refers to the perception of one's actual level of OCB engagement when compared with the average OCB engagement level of other members in the group. Additionally, we add task interdependence as a contextual contingency to further support to the link between positive OCB gab and task performance. The overall conceptual framework presented in Figure 1.

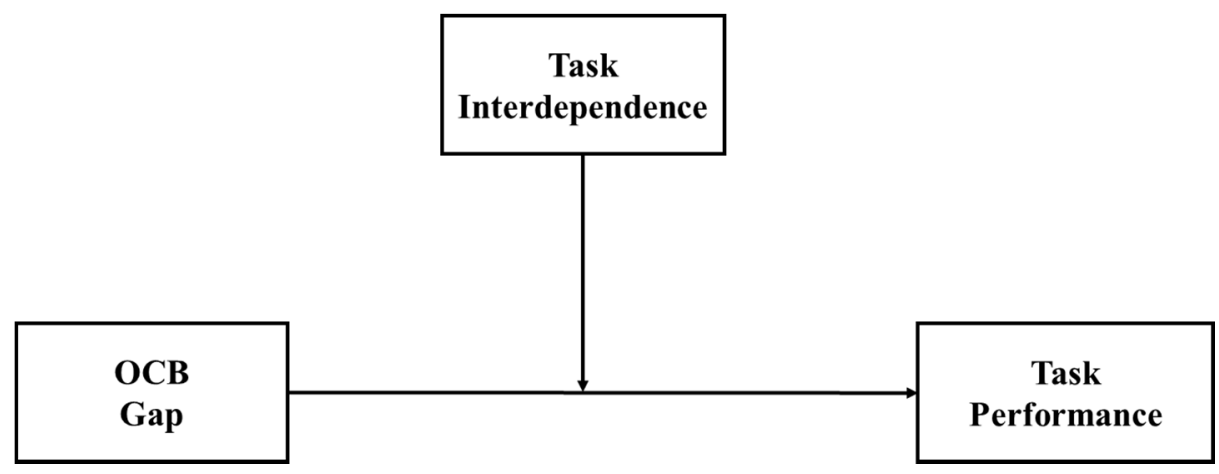

Figure 1. Conceptual framework.

\section{Background and Hypotheses}

After Bateman and Organ [1] introduced the concept of OCB, the dominance of team systems in the field of OCB research attracted the further interest of researchers toward OCB in a group context [12,19]. OCB in groups entails the exchange of favors that are discretionary and beneficial to other group members, which regulates social interactions among them. To understand OCB in group settings, therefore, it is important to understand the OCB that exists within group dynamics. Although a series of studies have investigated OCB, focusing on the group dynamics, such as the OCB composition among group members or the relative OCB levels within teams [6,9], our understanding of OCB within group dynamics is still lacking. To elaborate our analyses and interpret OCB in group dynamics context, we adopted a social cognitive perspective and focused on how individual perceptions of OCB in group settings influence their behavior [10]. For this 
purpose, we suggested that the OCB gap reflects the individual perception of the difference in OCB levels among group members.

In this study, we propose the OCB gap as the perception of one's OCB in comparison to the OCB of other team members. Furthermore, we operationalize the OCB gap as a focal person's self-reported OCB subtracted from his/her group's mean OCB [11]. The perception that his/her coworkers have a higher level of OCB engagement that that of focal person, it can be perceived that the OCB gap is positive. In contrast, a negative OCB gap reflects the perception that the focal person engages in OCB more that his/her team members.

The effect of OCB on employee behavior has been well understood in extant studies over the past decades $[17,19,20]$. The rationale of why OCB may positively relate to employee performance has often been explained by social exchange theory [21]. Social exchange theory posits that the benefits received from other people evoke a sense of obligations in employees, which encourages them to reciprocate these benefits to the providing party either directly or indirectly $[13,19,21]$. For example, perceived organizational support is related to employee behaviors that are beneficial to the organization, such as job performance and OCB [22,23]. The perceived support of a team leader (high LMX) is positively related to behaviors that are favorable for the leader or the team since team leaders serve as proxies for the team [24,25]. Likewise, the support, reward, and other beneficial behaviors that individuals receive as results of their coworkers' OCB induces them to reciprocate in way that are favorable to the organization, leading to improved performance. In particular, the augmented feeling of indebtedness is only induced when employees perceive that their coworkers engage in OCB more often than they do, as in a positive OCB gap situation. Otherwise, individuals tent to feel that other people are obligated to reciprocate any positive OCB they receive.

A positive OCB gap implies that coworkers spend more of their energy, time, and other resources on helping their colleagues to complete or improve their respective performance $[18,26]$. Since OCB is a discretionary behavior, the perception of a positive OCB gap will be appreciated by employees and evoke a strong intention to reciprocate [18]. According to Molm [21], the exchange of favors among individuals may take several forms, including direct and indirect exchange. In organizational teams, OCBs are often directed at job performance or the organization itself rather than a specific individual. Therefore, as a way to reciprocate work related help received from their coworkers, employees who perceive a positive OCB gap will contribute to the group as a whole and exert more efforts to improve their performance instead of or in addition to reciprocating directly to the giver. Thus, the perception of a positive OCB gap is expected to be positively related to task performance, which has obvious benefits for the team members who provide their coworkers with additional help. Therefore, we hypothesized the following hypothesis:

\section{Hypothesis 1. The OCB gap is positively related to employees' task performance.}

Although Podsakoff and colleagues [5] suggested that contextual factors such as task interdependence [27-29] may affect the influence of OCB on employee performance, the issue of contextual moderation has only received limited attention in the OCB literature $[16,17,30]$. Task interdependence has been conceptualized as the extent to which employees need to cooperate with other members to accomplish their work effectively [28]. As one of the more important contextual factors for teams [31], the influence of task interdependence on employee performance has attracted significant research attention $[15,31,32]$. Over time, researchers have shown that task interdependence has diverse effects, such as encouraging team members to be more cooperative [15], making employees more willing to share their knowledge with their coworkers [33]. Task interdependence is also a critical factor that influences job performance [34]. Based on these arguments and the available empirical results, there is strong evidence that the task interdependence perceived by group members affects the influence of OCB on task performance $[15,17]$. 
Task interdependence is related to high ratings in terms of the importance of OCB [15], implying that people value OCB more when the task is interdependent in nature. When tasks are interdependent, team members should interact closely with each other to complete tasks, which presents them with more chances to compare each other's citizenship behavior [35]. Thus, task interdependence provides a context wherein citizenship behavior can be distinguished. We assessed task interdependence by asking individuals if their respective performance affected the performance of others and whether collaboration with other team members was essential for successful task completion [36]. Consequently, when task interdependence is high, the value of a positive OCB gap tends to be more appreciated. This high level of appreciation generates a stronger sense of reciprocity among employees, which naturally results in their extra effort to return the favor to the group and its members with their performance.

When task interdependence is high, employees benefit more from the information and resources provided by their coworkers [37]. When there is a positive OCB gap, employees can utilize the additional information and materials received from their coworkers to perform the task more effectively, provided that the task is interdependent. When task interdependence is low, on the other hand, excessive help and resources from team members may be interpreted as nosy interference and may not effectively help employee performance.

Thus, task interdependence may moderate the effect of the OCB gap on employee performance. In addition to the fact that task interdependence should impact the absolute level of benefit that employees may enjoy from a positive OCB gap, employees tend to have a greater appreciation of their coworkers' OCB when working on interdependence task. Therefore, when the task is interdependent in nature, employees will be more strongly motivated to pay back the favors received from their coworkers and will exert more effort in their task performance. When the task is independent in nature, the actual benefit that employees receive from their coworkers' additional OCB will be smaller. Accordingly, employees will be less motivated to return this extra support and thus will exert less efforts on task performance.

Hypothesis 2. Task interdependence moderates the relationship between the OCB gap and employees' job performance, such that the relationship is stronger when task interdependence is high rather than low.

\section{Methodology}

\subsection{Samples}

In this study, the data were collected from different Korean organizations from the manufacturing, electronics, and telecommunication industries. The wide variety of data used for the current study increased the generalizability of the study results. To reduce common method bias, we administered two sets of the survey: one to the employees of the selected organizations and the other to their immediate supervisors. Trained researchers visited the contacted organizations and distributed two sets of the paper-based surveys to the participants. All participants received a brief documentation that informed them of the purposes of this study and guaranteed the confidentiality of their responses. When they completed the questionnaire, the participants were urged to seal their survey envelope and to return the survey directly to the trained researchers.

Out of the 160 sets of surveys distributed, 150 completed sets were returned (manager response rate $=97.7 \%$; employee response rate $=93.8 \%$ ). After excluding incomplete responses and unmatching the data from the supervisory ratings, we obtained a final sample of 146 employees working in 41 teams. Among these employees, 54.1\% were male, with the participants having an average age of 34.9 years $(\mathrm{SD}=5.45)$, and had an average organizational tenure of 6.0 years $(\mathrm{SD}=5.45)$. Among the respondents, the highest level of education was high school, a two-year college education, a bachelor's degree, and a master's degree or doctorate for 1.4, 23.3, 63.7 and $11.6 \%$ of the respondents, respectively. 


\subsection{Measures}

By following Brislin's [38] procedure, all the survey items were back-translated. Except for the demographic data, the responses for all items were provided on a seven-point scale ranging from 1 (not at all) to 7 (extremely).

Organizational Citizenship Behavior. Individuals reported their OCB using the 16-item scale $(\alpha=0.96)$ from Lee and Allen [39]. Example items include "Help others who have been absent" and "Express loyalty toward the organization".

OCB Gap. We computed the OCB gap by subtracting an individual's OCB from his/her group's mean OCB [40]. This value reflects the difference and distance between the individual and the aggregate OCB scores of the individuals. A positive OCB gap means that a group's mean OCB level is higher than the OCB level of individual team members.

Task Interdependence. Individuals were asked to examine their task interdependence using the four-item scale $(\alpha=0.91)$ from Pearce and Gregersen [36]. Example items include "The way individual members perform their jobs has a significant impact upon others in the group" and "I frequently must coordinate my efforts with others in my work group."

Task Performance. Immediate supervisors measured task performance of their employees using the seven-item scale $(\alpha=0.90)$ from Williams and Anderson [26]. Example items include "The subordinate adequately completes assigned duties" and "The subordinate meets formal performance requirements of the job."

Control Variables. To rule out any alternative explanations, we included the employees' demographic information (age, gender, organizational tenure, and education level) as control variables, which was suggested by prior OCB research $[19,20]$. Age and organizational tenure were measured in years. Gender was dummy coded as 0 for male and 1 for female. The education level was measured by the last education level achieved ((1) high school, (2) junior college, (3) undergraduate, (4) master's and doctoral degree).

\subsection{Analyses}

We found that the group-level variance, which is the proportion of the between-group variance in task performance in the total variance, was significant at $36.4 \%(p<0.001$, respectively). To rule out the supervisor effect in the outcome variable, all hypotheses were tested using a multi-stage analytical procedure via HLM [41,42]. First, to examine the main effect of the OCB gap on task performance, we included five control variables in Step 1 . Next, to test the moderating hypotheses, we included the moderating variable and interaction term in Steps 2 and 3. Finally, to interpret the moderating effect, we employed Aiken and West [43] procedure by drawing separate regression lines ( $\pm 1 \mathrm{SD})$.

\section{Results}

\subsection{Validity and Reliability Analysis Analyses}

To examine the validity of the measures, we conducted exploratory factor analysis (EFA). All items were rotated by varimax rotation under the assumption that there is no correlation among factors. We also measured the Cronbach's alpha to examine the reliabilities of measures. Table 1 presents the results of the EFA and the Cronbach's alpha values. All items were clearly loaded on three factors with a significantly high reliability coefficient. 
Table 1. The results of exploratory factor analyses.

\begin{tabular}{|c|c|c|c|c|}
\hline Iteams & $\begin{array}{c}\text { Factor } 1 \\
\text { (OCB) }\end{array}$ & $\begin{array}{c}\text { Factor } 2 \\
\text { (TP) }\end{array}$ & $\begin{array}{c}\text { Factor } 3 \\
\text { (TI) }\end{array}$ & $\begin{array}{c}\text { Cronbach's } \\
\text { Alpha }\end{array}$ \\
\hline OCB1 & 0.670 & 0.361 & 0.099 & \multirow{16}{*}{0.96} \\
\hline OCB2 & 0.723 & 0.429 & 0.029 & \\
\hline OCB3 & 0.685 & 0.511 & 0.001 & \\
\hline OCB4 & 0.727 & 0.371 & 0.092 & \\
\hline OCB5 & 0.621 & 0.505 & 0.063 & \\
\hline OCB6 & 0.637 & 0.443 & 0.096 & \\
\hline OCB7 & 0.665 & 0.502 & -0.029 & \\
\hline OCB8 & 0.610 & 0.485 & -0.057 & \\
\hline OCB9 & 0.602 & 0.561 & 0.109 & \\
\hline OCB10 & 0.693 & 0.472 & 0.125 & \\
\hline OCB11 & 0.865 & 0.216 & -0.029 & \\
\hline OCB12 & 0.811 & 0.332 & 0.148 & \\
\hline OCB13 & 0.830 & 0.300 & 0.019 & \\
\hline OCB14 & 0.850 & 0.257 & 0.057 & \\
\hline OCB15 & 0.814 & 0.359 & 0.013 & \\
\hline OCB16 & 0.796 & 0.262 & 0.151 & \\
\hline TP1 & 0.310 & 0.786 & -0.016 & \multirow{7}{*}{0.90} \\
\hline TP2 & 0.354 & 0.755 & 0.069 & \\
\hline TP3 & 0.443 & 0.682 & 0.063 & \\
\hline $\mathrm{TP} 4$ & 0.476 & 0.680 & 0.054 & \\
\hline TP5 & 0.500 & 0.452 & 0.095 & \\
\hline TP6 & -0.032 & 0.731 & 0.221 & \\
\hline TP7 & 0.066 & 0.746 & 0.153 & \\
\hline TI1 & 0.094 & 0.076 & 0.812 & \multirow{4}{*}{0.91} \\
\hline TI2 & 0.064 & 0.057 & 0.932 & \\
\hline TI3 & 0.067 & 0.058 & 0.928 & \\
\hline TI4 & 0.113 & 0.058 & 0.893 & \\
\hline Eigenvalues & 8.113 & 7.475 & 3.393 & \\
\hline $\begin{array}{c}\text { Variance } \\
\text { explained (\%) }\end{array}$ & 30.047 & 27.686 & 12.568 & \\
\hline $\begin{array}{l}\text { Accumulative } \\
\text { variance } \\
\text { explained (\%) }\end{array}$ & 30.047 & 57.733 & 70.301 & \\
\hline
\end{tabular}

\subsection{Discriptives Statistics}

Table 2 provides the means, standard deviations, and zero-order correlations of the variables in this study. The correlations were generally consistent with the study hypotheses. The OCB gap found to be positively correlated with task interdependence $(\mathrm{r}=0.17, p<0.05)$ and task performance $(\mathrm{r}=0.38, p<0.001)$.

Table 2. Means, standard deviations, and inter-scale correlation.

\begin{tabular}{lcccccccc}
\hline & Mean & S.D. & $\mathbf{1}$ & $\mathbf{2}$ & $\mathbf{3}$ & $\mathbf{4}$ & $\mathbf{5}$ & $\mathbf{6}$ \\
\hline 1. Age & 34.90 & 6.73 & & & & & & \\
2. Gender & 0.48 & 0.54 & -0.05 & & & & & \\
3. Education & 2.86 & 0.62 & -0.10 & -0.08 & & & & \\
4. Tenure & 6.04 & 5.45 & $0.49 * * *$ & 0.01 & -0.12 & & & \\
5. OCB & 5.04 & 0.88 & -0.04 & $-0.19^{*}$ & $0.21^{*}$ & 0.14 & & \\
6. OCB gab & 0.01 & 0.51 & -0.07 & 0.09 & -0.15 & -0.06 & $-0.62^{* * *}$ & \\
7. Task & 4.86 & 1.02 & -0.11 & $-0.16^{*}$ & 0.05 & 0.13 & $0.18^{*}$ & $0.17^{*}$ \\
interdependence & 5.12 & 0.86 & -0.11 & -0.11 & 0.15 & 0.10 & $0.76^{* * *}$ & $0.38^{* * *}$ \\
8. Task performance & 5 & & & & $0.21^{*}$ \\
\hline
\end{tabular}

Note. $\mathrm{N}=146,{ }^{* * *}<0.001,{ }^{*}<0.05$. Two-tailed. 


\subsection{Hypotheses Testing}

The effect of OCB gap on task performance. Hypothesis 1 proposed that the OCB gap has a positive effect on task performance. After controlling the four demographical variables and OCB, we then entered the OCB gap as the main predictor in the HLM equations to predict task performance. As shown in Model 1 (Table 3), the OCB gap had a significant positive effect on task performance $(\gamma=0.26, p<0.05)$. Thus, Hypothesis 1 was supported.

Table 3. Hierarchical linear models predicting creativity.

\begin{tabular}{lccc}
\hline \multicolumn{1}{c}{ Variable } & Model 1 & $\begin{array}{c}\text { Task Performance } \\
\text { Model 2 }\end{array}$ & Model 3 \\
\hline Constant & $5.37^{* * * *}$ & $5.36^{* * * *}$ & $5.35^{* * *}$ \\
Age & -0.01 & -0.01 & -0.01 \\
Gender & 0.08 & 0.08 & 0.08 \\
Education & -0.02 & -0.02 & -0.01 \\
Tenure & 0.01 & 0.01 & 0.01 \\
OCB & $0.83^{* * *}$ & $0.83^{* * *}$ & $0.82^{* * *}$ \\
OCB gap & $0.26^{*}$ & $0.26^{*}$ & $0.25^{*}$ \\
Task interdependence (TI) & & 0.07 & 0.07 \\
OCB gap X TI & & & $0.16^{* *}$ \\
Pseudo R square & 0.05 & 0.05 & 0.06 \\
\hline Note. N $=146^{* * *}<0.001^{* *}<0.01 *<0.05$, two-tailed & &
\end{tabular}

The moderating effect of task interdependence. Hypothesis 2 proposed that the task interdependence has a positive moderating effect on the relationship between the OCB gap and task performance. The results in Model 3 of Table 3 shows that the moderation role of task interdependence in predicting the main effect was significant $(\gamma=0.16, p<0.01)$. To further explore this moderating effect, we plotted the simple slopes of two levels of task interdependence: one standard deviation above and below the mean [42]. As shown in Figure 2, there was a significant positive relationship between the OCB gap and task performance in a high task interdependence context $(b=0.41, p<0.001)$, however, this relationship was insignificant when task interdependence was low $(b=0.09$, ns). Thus, Hypothesis 2 was supported.

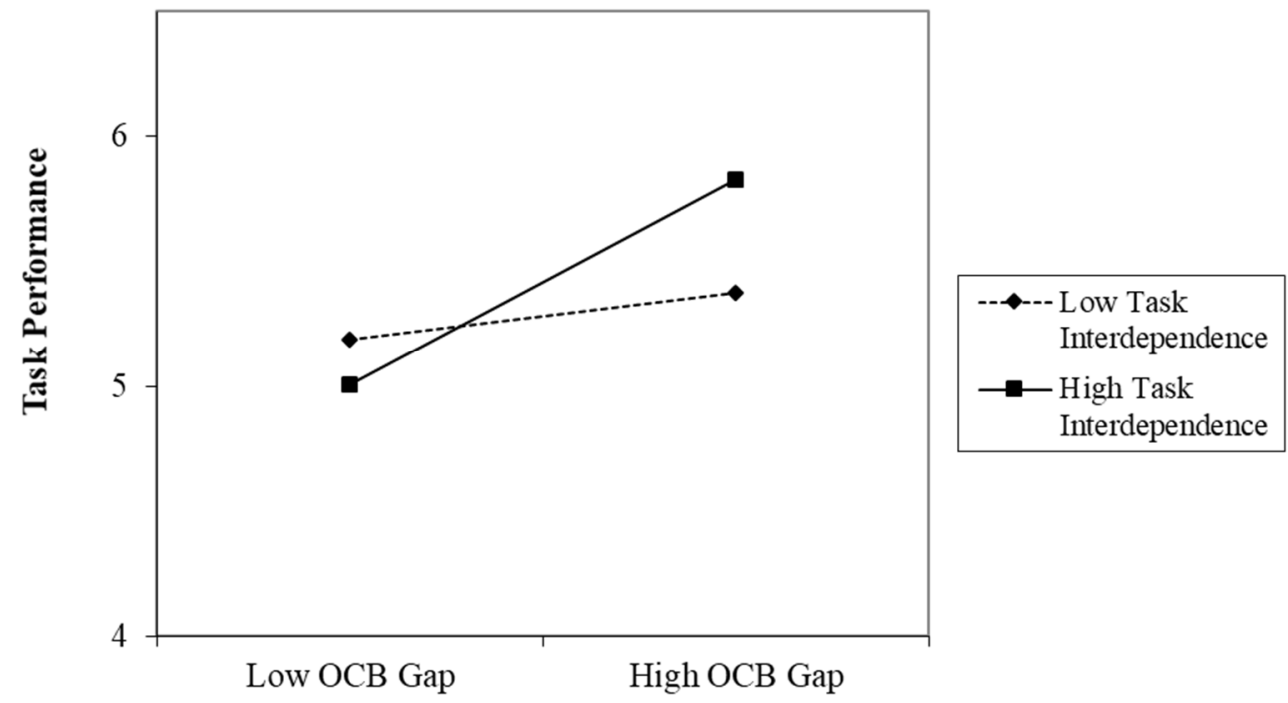

Figure 2. Interaction of OCB Gap and Task Interdependence on Task Performance. 


\section{Discussion}

\subsection{Overall Findings}

Since its introduction in the sixties, OCB has attracted in the interest of many scholars and is still one of the most popular topics in organizational behavior studies [2,3]. OCB has yet been investigated within teams from a social cognitive perspective even after decades of studies. With the increasing dominance of team systems in contemporary organizations, inter-member dynamics have gained increasing importance. In particular, employee perceptions of the OCB of other members in a team are likely to influence their organizational behaviors. We hypothesized and demonstrated that how the OCB gap can be utilized to predict the job performance of team workers keeping this issue in mind. We also investigated the moderating effect of task interdependence on the relationship between the OCB gap and task performance.

As hypothesized, we found that the OCB gap was positively related to task performance. The findings revealed that when employees perceive that they are receiving favorable supports from their team members, they try to reciprocate this support by improving their performance [21]. In order to investigate the cognitive perception of the work context on the effect of the OCB gap, this study examined task interdependence as a moderating variable. We posited that high task interdependence increases the value of help and favorable support received from coworkers and thus, coworkers' OCB is more appreciated by the recipient parties. These results confirmed that the positive effect of the OCB gap on task performance is stronger when the task is interdependent in nature. In the following subsection, we highlight the theoretical and practical implications of this study and provide directions for future research.

\subsection{Implications for Theory and Practice}

By demonstrating that the OCB gap exerts a positive effect on individual task performance, this study represents the first attempt to empirically examine the social cognitive aspects of OCB within teams. Thus, the current study makes a major contribution in extending OCB studies regarding team dynamics by incorporating a social cognitive perspective. Departing from extant studies which considered the external existence of OCB among team members, this research focused on the internal perceptions and subsequent reactions of employees to the OCB gap among team members.

This study expands and contributes to the OCB literature based on social exchange theory. While extant studies investigated employee performance in the sense that the supervisors provide generous evaluations to employees who engaged in a high level of OCB [43], the present study is focused on the internal motivation of employees who perceived the OCB gap to reciprocate the benefits of coworker support by improving their task performance. Stronger reciprocal intention leads to improved task performance, especially due to the invaluable support provided by coworkers in a high interdependence contest.

By confirming the moderating effect of task interdependence, this study revealed an important caveat: the interpretation of the coworker OCB gap among coworkers is dependent upon the attributes of the work context. In the previous literature, a number of studies empirically supported the notion that task interdependence has a positive effect on OCB on task performance. However, most of these studies found that, in high interdependence conditions, the cumulative $\mathrm{OCB}$ engagement level increased, resulting in improved team performance [15]. Rather than adding to these prolific studies, the current study focused on the perception of OCB among team members. It also successfully demonstrated that task interdependence strengthens the reciprocal motivation of employees who perceived a high OCB gap, leading to enhanced task performance.

Additionally, this study has several practical implications for employee management. First, organizations may choose to place emphasis on employee OCB since organizational emphasis on OCB will make team members' citizenship behaviors more noticeable to each other. Employees are more inclined to compare their own OCB engagement levels with those of their coworkers when the OCB of other team members is more visible and are 
more likely to perceive a high OCB gap. Second, by demonstrating that task performance is dependent on a combination of OCB gap and task interdependence, this study has significant practical managerial value. Managers may want to consider both OCB and task interdependence in their workplace to increase their employees' performance

\subsection{Limitations and Directions for Future Research}

Although this research contributes a new perspective to OCB research, it has certain limitations to note. First, since this study utilized cross-sectional data that were collected from several organizations, the causal relationship among the data should be interpreted with care. Although these relationships were theoretically supported in this study, the nature of cross-sectional data may limit the clear causal inferences that could be derived from the data. Thus, future research should use a time-lagged data to rule out any potential issues related to reverse causality.

Second, the current research explored the effect of the OCB gap on task performance. The perception of employees' OCB engagement at Time 1 may further influence their OCB engagement at Time 2. For example, employees who perceive that they exhibit a lower OCB engagement level than the average engagement level of their coworkers may seek to improve their OCB engagement. Future studies could further elaborate the understanding of the OCB gap by investigating the OCB gap at Time 1 and Time 2.

Finally, we utilized an indirect gap measure by subtracting the self-measured OCB of team members from the team's average self-measured OCB value. Although this type of indirect measure has been widely used in prior literature to measure differences in perception, using a direct assessment of the perception gap may provide a more proximal measure of team members' attitudes and behaviors [11]. Future researchers may further examine the effect of the OCB gap using a direct measure, which may directly ask individuals about their perception of the relative OCB differences among members.

In contemporary organizations, the interpersonal dynamics among team members are regarded as the cornerstone of team performance [5,6]. This study offers novel insights into how OCB differences among members may affect employee performances. We also validated the distinct role that task interdependence has on employee reactions to the OCB gap. This study paves the way for further theoretical and empirical endeavors aimed at understanding the complex inter-member dynamics present within organizational teams.

Author Contributions: All of the authors contributed immensely. Y.Y. wrote the majority of the manuscript; H.C. conducted statistical analysis and revised the manuscript. All authors have read and agreed to the published version of the manuscript.

Funding: This research received no external funding.

Institutional Review Board Statement: Not applicable.

Informed Consent Statement: Not applicable.

Data Availability Statement: Not applicable.

Conflicts of Interest: The authors declare no conflict of interest.

\section{References}

1. Bateman, T.S.; Organ, D.W. Job satisfaction and the Good Soldier: The Relationship between Affect and Employee "Citizenship". Acad. Manag. J. 1983, 26, 587-595. [CrossRef]

2. Morrison, E. From the editors: OB in AMJ: What is hot and what is not? Acad. Manag. J. 2010, 53, 932-936. [CrossRef]

3. Carpenter, N.C.; Berry, C.M.; Houston, L. A meta-analytic comparison of self-reported and other-reported organizational citizenship behavior. J. Organ. Behav. 2014, 35, 547-574. [CrossRef]

4. Choi, J.N.; Sy, T. Group-level organizational citizenship behavior: Effects of demographic faultlines and conflict in small work groups. J. Organ. Behav. 2010, 31, 1032-1054. [CrossRef]

5. Podsakoff, N.P.; Podsakoff, P.M.; MacKenzie, S.B.; Maynes, T.D.; Spoelma, T.M. Consequences of unit-level organizational citizenship behaviors: A review and recommendations for future research. J. Organ. Behav. 2014, 35, S87-S119. [CrossRef] 
6. $\mathrm{Ng}$, K.Y.; Van Dyne, L. Antecedents and performance consequences of helping behavior in work groups: A multilevel analysis. Group Organ. Manag. 2005, 30, 514-540. [CrossRef]

7. Borman, W.C.; White, L.A.; Dorsey, D.W. Effects of ratee task performance and interpersonal factors on supervisor and peer performance ratings. J. Appl. Psychol. 1995, 80, 168-177. [CrossRef]

8. Jacobson, R.P.; Jacobson, K.J.; Hood, J.N. Social norm perceptions predict citizenship behaviors. J. Manag. Psychol. 2015, 30, 894-908. [CrossRef]

9. Raver, J.L.; Ehrhart, M.G.; Chadwick, I.C. The emergence of team helping norms: Foundations within members' attributes and behavior. J. Organ. Behav. 2012, 33, 616-637. [CrossRef]

10. Bandura, A. Social Foundations of Thought and Action: A Social Cognitive Theory; Englewood Cliffs: Prentice Hall, NL, USA, 1986.

11. Kristof-Brown, A.L.; Zimmerman, R.D.; Johnson, E.C. Consequences of individuals' fit at work: A meta-analysis of person-job, person-organization, person-group, and person-supervisor fit. Pers. Psychol. 2005, 58, 281-342. [CrossRef]

12. Nielsen, T.M.; Hrivnak, G.A.; Shaw, M. Organizational citizenship behavior and performance: A meta-analysis of group-level research. Small Group Res. 2009, 40, 555-577. [CrossRef]

13. Blau, P.M. Power and Exchange in Social Life; John Wiley \& Sons: New York, NY, USA, 1964.

14. Gouldner, A.W. The norm of reciprocity: A preliminary statement. Am. Sociol. Rev. 1960, 25, 161-178. [CrossRef]

15. Bachrach, D.G.; Powell, B.C.; Collins, B.J.; Richey, R.G. Effects of task interdependence on the relationship between helping behavior and group performance. J. Appl. Psychol. 2006, 91, 1396-1405. [CrossRef]

16. Bolino, M.C.; Turnley, W.H.; Bloodgood, J.M. Citizenship behavior and the creation of social capital in organizations. Acad. Manag. Rev. 2002, 27, 505-522. [CrossRef]

17. Podsakoff, P.M.; MacKenzie, S.B.; Paine, J.B.; Bachrach, D.G. Organizational citizenship behaviors: A critical review of the theoretical and empirical literature and suggestions for future research. J. Manag. 2000, 26, 513-563. [CrossRef]

18. Organ, D.W. Organizational Citizenship Behavior: The Good Soldier Syndrome; Lexington Books: Lexington, MA, USA, 1988.

19. Choi, J.N. Collective Dynamics of Citizenship Behaviour: What Group Characteristics Promote Group-Level Helping? J. Manag. Stud. 2009, 46, 1396-1420. [CrossRef]

20. Podsakoff, N.P.; Whiting, S.W.; Podsakoff, P.M.; Blume, B.D. Individual- and organizational-level consequences of organizational citizenship behaviors: A meta-analysis. J. Appl. Psychol. 2009, 94, 122-141. [CrossRef]

21. Molm, L.D. Experiments on exchange relations and exchange networks in sociology. In Laboratory Experiments in the Social Sciences, 1st ed.; Webster, M., Sell., J., Eds.; Academic Press: New York, NY, USA, 2014; pp. 199-224.

22. Eisenberger, R.; Armeli, S.; Rexwinkel, B.; Lynch, P.D.; Rhoades, L. Reciprocation of perceived organizational support. J. Appl. Psychol. 2001, 86, 42-51. [CrossRef]

23. Settoon, R.P.; Bennett, N.; Liden, R.C. Social exchange in organizations: Perceived organizational support, leader-member exchange, and employee reciprocity. J. Appl. Psychol. 1996, 81, 219-227. [CrossRef]

24. Chen, Z.; Lam, W.; Zhong, J.A. Leader-member exchange and member performance: A new look at individual-level negative feedback-seeking behavior and team-level empowerment climate. J. Appl. Psychol. 2007, 92, 202-212. [CrossRef]

25. Wang, L.C.; Hollenbeck, J.R. LMX in team-based contexts: TMX, authority differentiation, and skill differentiation as boundary conditions for leader reciprocation. Pers. Psychol. 2019, 72, 271-290. [CrossRef]

26. Williams, L.J.; Anderson, S.E. Job satisfaction and organizational commitment as predictors of organizational citizenship and in-role behaviors. J. Manag. 1991, 17, 601-617. [CrossRef]

27. Organ, D.W.; Podsakoff, P.M.; MacKenzie, S.B. Organizational Citizenship Behavior: Its Nature, Antecedents, and Consequences; Sage Publications: Beverly Hills, CA, USA, 2006.

28. Thompson, J.D. Organizations in Action: Social Science Bases of Administrative Theory; McGraw-Hill: New York, NY, USA, 1967.

29. Wageman, R. Interdependence and group effectiveness. Adm. Sci Q. 1995, 40, 145-180. [CrossRef]

30. Colomer, J.; Serra, T.; Cañabate, D.; Bubnys, R. Reflective learning in higher education: Active methodologies for transformative practices. Sustainability 2020, 12, 3827. [CrossRef]

31. Langfred, C.W. Autonomy and performance in teams: The multilevel moderating effect of task interdependence. J. Manag. 2005, 31, 513-529. [CrossRef]

32. Vidyarthi, P.R.; Singh, S.; Erdogan, B.; Chaudhry, A.; Posthuma, R.; Anand, S. Individual deals within teams: Investigating the role of relative i-deals for employee performance. J. Appl. Psychol. 2016, 101, 1536-1552. [CrossRef] [PubMed]

33. Crawford, J.L.; Haaland, G.A. Predecisional information seeking and subsequent conformity in the social influence process. J. Pers. Soc. Psychol. Manag. 1972, 23, 112-119. [CrossRef]

34. Gully, S.M.; Devine, D.J.; Whitney, D.J. A meta-analysis of cohesion and performance: Effects of level of analysis and task interdependence. Small Group Res. 2012, 43, 702-725. [CrossRef]

35. Liden, R.C.; Wayne, S.J.; Bradway, L.K. Task interdependence as a moderator of the relation between group control and performance. Hum Relat. 1997, 50, 169-181. [CrossRef]

36. Pearce, J.L.; Gregersen, G. Task interdependence and extrarole behavior: A test of the mediating effects of felt responsibility. J. Appl. Psychol. 1991, 76, 838-844. [CrossRef]

37. Ozer, M.; Chang, C.; Schaubroeck, J.M. Contextual moderators of the relationship between organizational citizenship behaviours and challenge and hindrance stress. J. Occup. Organ Psychol. 2014, 87, 557-578. [CrossRef] 
38. Brislin, R.W. The wording and translation of research instruments. In Field Methods in Educational Research; Lonner, W.J., Cerry, J.W., Eds.; Sage: Newbery Park, CA, USA, 1986; pp. 137-164.

39. Lee, K.; Allen, N.J. Organizational citizenship behavior and workplace deviance: The role of affect and cognitions. J. Appl. Psychol. 2002, 87, 131-142. [CrossRef] [PubMed]

40. Song, G.R.; Kim, K.S. More Similar, Better Belonging: Effect of Organizational Citizenship Behavior Profile Similarity on Ostracism. J. Appl. Behav. Sci. 2002, 23, 1-19. [CrossRef]

41. Bryk, A.S.; Raudenbush, S.W. Hierarchical Linear Models: Applications and Data Analysis Methods; Sage: Newbury Park, CA, USA, 1992.

42. Hair, J.F.; Black, W.C.; Babin, B.J.; Anderson, R.E.; Latham, R.L. Multivariate Data Analysis; Prentice-Hall: Upper Saddle River, NJ, USA, 2014.

43. Aiken, L.S.; West, S.G. Multiple Regression: Testing and Interpreting Interactions; Sage: Newbury Park, CA, USA, 1991. 